\title{
ORAÇÃO EM HOMENAGEM A NELSON MANNRICH NA POSSE SOLENE COMO TITULAR DE DIREITO DO TRABALHO, DA FACULDADE DE DIREITO DA UNIVERSIDADE DE SÃO PAULO
}

\author{
Ada Pellegrini Grinover \\ Professora Titular de Direito Processual da \\ Faculdade de Direito da Universidade de São Paulo, \\ Pró-Reitora de Graduação da Universidade de São Paulo.
}

\begin{abstract}
Abrem-se, mais uma vez, as portas do suntuoso Salão Nobre da Faculdade de Direito do Largo de São Francisco, a fim de a Congregação receber solenemente seu novo titular de Direito do Trabalho, o Professor Doutor Nelson Mannrich. Seus pares e os demais professores aguardam-lhe a manifestação, que terá sabor de juramento. Familiares e amigos estão emocionados, lembrando os caminhos, freqüentemente ásperos, que trouxeram seu ente querido até aqui. Os estudantes, em respeitoso silêncio, querem prestar ao Mestre um preito de homenagem e agradecimento. Os funcionários participam com alegria desse momento feliz. Este membro da Congregação, que vos fala, sente-se honrada pela designação e sensibilizada pela demonstração de carinho do novo professor titular, que a escolheu. E ele, o que sente ele? Quais as emoções e os sentimentos que se agitam em seu peito? Quais os pensamentos que povoam sua mente? Quais as sensações que perpassam seu ser?

Cada um de nós, os professores titulares que passamos por este momento, sabe que ele é feito de um misto indescritivel de expectativas, de responsabilidade, de empenho, de alegria e de ansiedade. De lembranças do passado e de projetos para o futuro. É uma fase que se fecha - caminho feito de dificuldades, ganhos e perdas - e outra que se abre - caminho feito de desafios, estimulantes e assustadores. Mas cada um de nós, que passou por esse momento, foi e é uma pessoa diferente de qualquer outra, senhora de experiências diversas das dos outros, moldada pela vida de forma muito peculiar, tendo que construir passo a passo sua trajetória à sua maneira, fazendo suas escolhas, às vezes dolorosas, traçando seu caminho em meio a mil dificuldades, que também não são iguais para todos.

É isto que torna cada cerimônia de recepção dos novos professores titulares, nesta Casa onde por mais de 170 anos vieram se repetindo solenidades como
\end{abstract}


esta, um momento novo, surpreendente, único. Porque sempre novo, surpreendente, único é o ser humano, por mais que a pompa e circunstância possam ser as mesmas, por mais que os rituais sigam a tradição, por mais que a alegria, a ansiedade, a emoção possam parecer universais. Cada homem é um homem, resultado daquilo que the é inato e daquilo que adquiriu durante a vida, rico de experiências pessoais e moldado pelo meio em que viveu, só - às vezes - em meio aos outros, comunicando-se freqüentemente - com os outros, mas sempre ele mesmo e diferente de todos os outros.

Por isso, para entender esse momento, vale saber quem é o homem que a Congregação está recebendo. De onde veio, como se forjou nas tempestades e bonanças da vida, quais os caminhos que percorreu para chegar até aqui. Conhecendo-o melhor, poderemos dar um sentido diverso a essa cerimônia e não considerá-la apenas uma dentre tantas e tantas outras. Poderemos viver um momento único, como único é Nelson Mannrich.

Convido-vos, Senhoras e Senhores, a uma viagem no tempo. Vamos encontrar o pequeno "Doutor Celso" como se assinava tão-logo aprendeu a escrever, na escola rural do Alto Vale do Itajaí, numa colônia alemã de Santa Catarina. "Doutor Celso" o que isso significa? Celso, porque com esse nome o quisera registrar o pai, muito embora o oficial do registro civil tivesse preferido escrever "Nelson". Não ficava bem, para um neto de alemães, logo depois da guerra, levar o nome do almirante inglês e ele foi Celso até a juventude. O choque foi grande quando, aos 12 anos, o pequeno soube que seu nome havia sido trocado, mas não se perturbou. Continuou dizendo a todos que se chamava Celso e o assunto ficou resolvido, até que uma namorada, nas trilhas do que havia sido deliberado pelo Brasil oficial, resolveu que se era Nelson, Nelson seria, e ponto final. Conformou-se mas, mais tarde, batizaria como Celso o primeiro filho homem. E porquê Doutor? Porque aos 6 anos, ele já acalentava um sonho, que era, na verdade, uma vocação: a de ser advogado.

Mas, como continuar os estudos após o primário? Com oito irmãos, numa família de agricultores, as perspectivas não eram das melhores. Até que um dia, quando estava no quarto ano, apareceu na escola um irmão marista, com a função de recrutar meninos para o seminário de São Bento do Sul. Levava fotos, descrevia uma vida laboriosa e serena, falava em estudos gratuitos e em vocações. O pequeno Celso não viu dificuldades em conciliar seu sonho de ser advogado com a vida religiosa e seguiu viagem, feliz, com um bando de garotinhos, embarcando num trem como numa aventura. E se deu bem.

A vida comunitária, o esporte, a disciplina, as orações, os sólidos estudos, incluindo latim e francês, música e poesia, o trabalho no campo, tudo caiu no seu 
gosto. Com o noviciado, a vida se tornou mais dura: o silêncio, as leituras e a perspectiva de continuar apenas os estudos religiosos. Como se tornar advogado? Escolhido para o seminário de Caxias do Sul, conseguiu cursar a Escola Normal em colégio de freiras e o clássico à noite. De tarde, estudava francês e inglês. Começou a perceber que a vocação para os estudos jurídicos era mais forte do que a religiosa, e fez sua escolha. Ganhava dinheiro, ministrando aulas e usando o mimeógrafo para reproduzir textos escolares. Queria ser marista, mas sem abdicar de ser advogado. Foi enviado para o Seminário de Senhor do Bonfim, na Bahia, para que tirasse o Curso de Direito da cabeça. Em vão. Finalmente os religiosos tiveram que se conformar e, depois de chamálo de volta a Caxias do Sul, o dispensaram, antes que proferisse os votos definitivos. Deixou a vida religiosa com outros jovens que queriam cursar a faculdade, mas o grupo se dispersou e ele se viu sozinho. Onde estudar? Escolheu logo a Faculdade de Direito da Universidade de São Paulo.

E aqui chegou o jovem Celso - que ainda não era Nelson - em busca da Faculdade, que foi procurar no campus da ... Cidade Universitária. Não desanimou e finalmente conseguiu aportar no Largo de São Francisco. Era o fim do ano de 1968 e, adentrando as Arcadas, o moço perguntou à primeira pessoa que viu - provavelmente um funcionário - o que era preciso fazer para cursar Direito. O desconhecido olhou para aquele loiro, alto, com cara de alemão, certamente um imigrante, e resolveu complicar:

Você quer estudar Direito para quê?

Quer ser político ou advogado?

Advogado - respondeu o jovem sem a menor hesitação.

Então você não deve estudar aqui. Seu lugar é na PUC.

E assim foi que Nelson (ex-Celso) cursou Direito na PUC.

Foi um novo deslumbramento. Lançava-se nos dias de sua chegada a São Paulo a pedra fundamental do metrô. E o moço interpretou a coincidência como um prenúncio de mudanças radicais para ele também. Ganhou bolsas no cursinho e na Faculdade como melhor aluno. E percebeu que limitar-se ao Direito seria simples demais. Cursou Sociologia com os jesuítas, fez cursos de Teologia e não desprezou a taquigrafia. Manteve a bolsa até perdê-la por ter sido mandado para o oral numa matéria. Quê matéria? Direito do Trabalho... Qual o professor? Cássio Mesquita Barros...

Compensaria esse revés mais tarde, com o convite do próprio professor para trabalhar em seu escritório.

Mas, por enquanto, era preciso pagar a Faculdade. Numa missa na Igreja Nossa Senhora de Loreto, em Vila Medeiros, ouviu o padre João avisando que em 
breve se iniciaria o curso preparatório para os exames de admissão ao ginásio. Foi dito e feito: o jovem ex-marista tinha todas as qualificações para ministrar aulas. De tarde, arrumou trabalho num Banco. Começou a ganhar um dinheirinho, até fazer um curso de corretor de valores e passar a vender fundos de investimentos. Com o bom dinheiro arrecadado, trouxe dois irmãos de Santa Catarina, que sustentou e encaminhou na vida Dois episódios marcantes dessa fase: as maiores vendas, sempre feitas aos irmãos maristas e a triste perda de um prêmio vultuoso como corretor. Tinha uma namorada, à época, reticente sobre a própria idade, que, generosamente, se ofereceu para comprar as ações necessárias à percepção do prêmio. Foi necessário pedir-lhe a cédula de identidade, pela qual, chocado, se deu conta de que a moça tinha dez anos mais do que ele. A pietas romana e a caridade cristã falharam naquele momento crucial: e ele perdeu, ao mesmo tempo, o negócio e a namorada...

Formado, a vida profissional ia de vento em popa: o escritório Mesquita Barros/Magano, onde ficou um ano; o Sindicato dos Metalúrgicos de São Bernardo, onde foi entrevistado por Lula e trabalhou com Almir Pazzianotto durante cinco anos; concomitantemente, o cargo público de inspetor do Trabalho, do Ministério do Trabalho, no qual se aposentaria. Começou a carreira universitária, agora já na Faculdade de Direito da USP, como orientado do professor Cássio, em Direito do Trabalho, em 1974. Iniciou as atividades acadêmicas, lecionando no Mackenzie, em substituição ao professor Luiz Carlos Robortella, e na UNESP, em Franca. Mais tarde se tornaria professor da Fundação Getúlio Vargas e abriria o Curso Preparatório para Concursos Mannrich e Robortella. Mas, enquanto isso, sua vida pessoal se transformava num calvário.

Casado em 1976, já com uma filha - Luciana - e logo após o nascimento de Celso, o médico lhe comunicou uma verdadeira tragédia: a mulher era portadora de uma grave doença degenerativa, a esclerose múltipla, irreversível e fatal. Em breve, a esposa não conseguiu mais andar e, após alguns meses, ficou relegada permanentemente a uma cama, sobre um colchão de água. Foram anos de sofrimento, em que cuidou dela, dos filhos, da casa, mantendo a família unida apesar das inúmeras dificuldades. Foi enfermeiro, dono de casa, pai e mãe de crianças que só conheceram a pobre criatura, durante um breve período, em cadeira de rodas e depois, pelo resto da vida, inanimada, numa cama. Nesses anos de atribulações, o homem forte, profundamente religioso, educado na disciplina e na fé, forjado pelas dificuldades da vida, lutou e ganhou, junto a seus filhos, ensinando-lhes o amor à mãe. E só mais tarde, sem jamais abandonar a mulher e sempre cuidando dela pessoalmente, refez sua vida ao lado de outra pessoa, que the deu outro filho, André. 
Entre todos esses percalços, conseguiu defender a dissertação de mestrado, nas Arcadas, em 1982. O doutorado só veio em 1991. A Livre-Docência em 1997 e o cargo de titular, em 1999. Mas sua produção científica sempre foi do mais elevado nível.

Inúmeros artigos de alta qualidade, diversos capítulos de livros, os volumes sobre Inspeção do Tiabalho e A Modernização do Contrato de Trabalho, conferências, palestras, participações em congressos, envolvimento em comissões de estudos e bancas examinadoras e, acima de tudo, as atividades didáticas pelas quais se notabilizou junto aos alunos, que por várias vezes o homenagearam.

Este, Senhoras e Senhores, é o homem, o estudioso, o jurista, o professor que a Congregação da Faculdade de Direito do Largo de São Francisco se preza de receber hoje. Agora sabemos de onde ele veio e a que veio. E podemos dar a esta cerimônia o sentido adequado à personalidade de um homem probo, justo, generoso, bom, obstinado e lutador que certamente fará, da conquista de hoje, não um ponto de chegada, mas sim um ponto de partida, do qual tomará impulso para enfrentar e vencer desafios ainda maiores.

Sede bem vindo, Professor Titular Nelson Mannrich: ad sidera!

São Paulo, 17 de agosto de 2001 


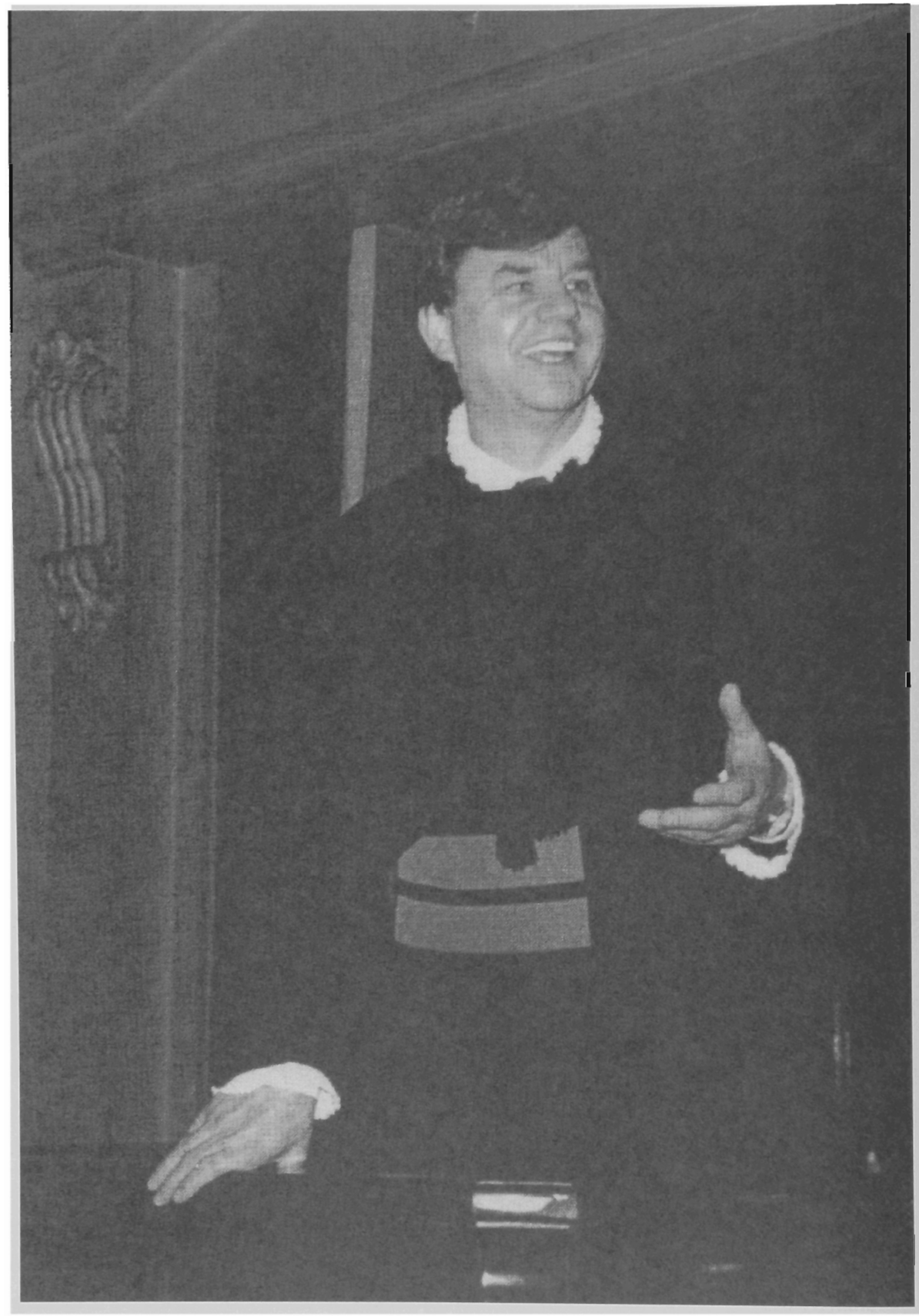

Professor Doutor Nelson Mannrich 